\title{
The key challenges to utilize innovative opportunities of small and medium sized enterprises in Surabaya, Indonesia
}

\author{
Prita Ayu Kusumawardhany \\ University of Surabaya, Surabaya, Indonesia
}

\begin{abstract}
The world has entered an era of disruptive innovation where transformation is needed. In the conceptual age, a business needs to have new experiences and create ideas. This paper aims to identify the most important challenges of Small Medium-Sized Enterprises (SMEs) in utilizing innovative opportunities. The main issue facing many SMEs - industrial and service with less than 50 employees, is how they can nurture effective innovation. There were 118 questionnaires distributed and gathered from SMEs in Surabaya, Indonesia. This research used factor analysis which shows the six main challenges: lack of managerial training and experience, inadequate education and skills, national policy and regulatory environment, technological change, lack of market information, and lack of credit. A qualitative approach through interview was also used for interpretation of data. In conclusion, human capabilities and intelligence are not enough to compete but require technology and information to creatively transform.
\end{abstract}

Keywords: SMEs Challenges, Innovation, Innovative opportunities

\section{INTRODUCTION}

The rapid growth of economic globalization and technological developments make the competition increasingly tight. The competition requires businesses to continue making innovative products as well as improve performance, so it could increasingly provide benefits and convenience for customers in solving problems encountered.

Therefore, the importance of understanding the innovation competency for integrated service is necessary and is becoming more relevant as an engine of economic growth under the global change (Ko \& $\mathrm{Lu}$ 2010). Growing attention to innovation inclines companies to differentiate the value of existing products and services (Nybakk \& Jenssen 2012).

Small and Medium-Sized Enterprises (SMEs) face tremendous challenges in their attempt to pursue technological innovations.

Indonesia as a developing country now has various sectors that are progressing especially in economy. SMEs are generally regarded as the engine of economic growth and equitable development in developing economies. The government of Indonesia is now encouraging and more active in instilling entrepreneurship education to society. Surabaya is the only city awarded by UNESCO as Learning City.
One of the assessment factors was the number of SMEs that significantly grows. Current Surabaya

Mayor, Tri Rismaharini, encourages SMEs to further develop and promote their products through online or digital marketing.

On the other hand, rapid growth in the number of SMEs can satisfy a major increase in demand for its products and services or strengthen its competitive position. Growth is a critical step in the development of SME. In fact, the changes in economic and technological conditions can be a challenge that affects the viability of business because of instantaneous and unpredictable, often exceeding the capacity and capabilities of business to anticipate it.

This study used Farsi et al. (2014) titled "Identification the main challenges of small and mediumsized enterprises in exploiting of innovative opportunities (Case study: Iran SMEs)" as a reference which shows the main challenges. The Farsi et al. (2014) study result showed that SMEs in Iran faced some challenges as it suits the six main challenges. The two biggest challenges of SMEs for exploiting innovative opportunities are technological change and inadequate education and skills. 
This study aims to identify the most important challenges in utilizing innovative opportunities of SMEs in Surabaya, Indonesia. This research cannot be generalized to empirical research that examines the relationship between SMEs challenges and innovative opportunities.

\section{LITERATURE REVIEW}

\subsection{SMEs and Innovation Challenges}

SMEs face tremendous challenges in their attempt to pursue technological innovations. Innovation is also important at the micro level for companies as a key element in achieving sustainable competitive advantage (Maier et al. 2014). In today's world, it is nearly impossible for a single firm to generate all necessary substances for a successful innovation by only using its internal resources because products and services become more complex, thus for successful innovation, companies need to integrate knowledge from multiple disciplines (Howells et al. 2003). The accelerating pace of innovation causes a great pressure on companies to speed up their innovation processes. As a result of these changes in innovation landscape, innovation became more challenging, costly, and risky for companies (Sag et al. 2016).

Referring to Farsi et al. (2014), there are six main challenges as follows: (1) Lack of managerial training and experience that consists of management style, poor managerial ability, and lack of educational background; (2) Inadequate education and skills that consists of not quite well equipped in education and skills, lack of college level education; (3) National policy and regulatory environment that consists of unpredictable government policies and grand corruption; (4) Technological change consists of unfamiliarity with new technologies and either not locally available or not affordable or not situated to local condition; (5) Lack of market information that consists of lack of sufficient market information and poor connectivity; (6) Lack of credit which consists of lack of access to long term credit, lack freedom of choice, and undeveloped capital market.

\subsection{Innovation Opportunities}

An innovative opportunity is defined as "the possibility to realize a potential economic value inherent in a new combination of resources and market needs, emerging from changes in the scientific or technological knowledge base, customer preferences, or the interrelationships between economic actors. The concept of "innovative opportunities" comprises both aspects related to a potential market as well as aspects related to the scientific and technological knowledge needed to serve this specific market (Magnus et al. 2007). An innovative opportunity must consist of at least the following three conceptual elements in order for actors to have the possibility to identify, act upon, and realize the potential inherent in an idea: (1) An economic value for someone;

(2) A possibility that the resources needed to realize the opportunity can be mobilized; (3) A possibility that at least some parts of the generated economic value can be appropriated by the actor pursuing the opportunity (Farsi et al. 2014).

\section{METHODS}

This research was conducted using a case study approach. 118 questionnaires were distributed to SME owners in Surabaya because they have the most complete and up-to-date information upon the innovative development of their enterprises. The accuracy of responses was checked and only 100 respondents fulfilled the requirements, 18 respondents were removed.

Two methods were used for the purpose of this study. The first method was known as factor analysis in which PLS software was applied to assess the adequacy of measurement model based on the individual item and construct reliability, convergent validity and discriminant validity (Hulland 1999). The second method used was the qualitative method through interview six informants to interpret the results of factor analysis.

\section{RESULT AND ANALYSIS}

SME was categorized into two groups: manufacturing and services. According to Table 1, 79\% of respondents were manufacturers. Most of SMEs in Surabaya are producers of food and beverage. Most of the respondents have $1-9$ employees because Microenterprises are being supported by the Surabaya government. $35 \%$ of respondents were between 31 40 years old and most of them graduated from junior high school or higher education.

Table 1. Descriptive Data of Sample Population

\begin{tabular}{lcclc}
\hline Type of Firm & $\%$ & & Age & \\
\cline { 1 - 1 } Manufacturing & 79 & & $20-30$ & \\
Services & 21 & & $31-40$ & 17 \\
Total & 100 & & $41-50$ & 35 \\
& & & $>50$ & 30 \\
No. of Employees & $\%$ & & Total & 18 \\
$1-9$ & 82 & & Background &
\end{tabular}


Table 1, cont.

\begin{tabular}{lclc}
$10-19$ & 12 & Junior/Higher & 75 \\
$20-29$ & 3 & Bachelor & 24 \\
$30-39$ & 2 & Master & 1 \\
$40-49$ & 1 & Doctoral & 0 \\
Total & $\underline{100}$ & Total & $\underline{100}$ \\
\hline
\end{tabular}

The value of KMO was $80 \%$ and test value of Bartlet was significant to demonstrate valuable data for factor analysis. Composite reliability for all constructs should be more than 0.707 which is considered as cut off point (Alizadeth et al. 2011). The results of Cronbach's Alpha also support the reliability of all constructs. Based on table 2, AVE for all constructs is more than 0.5 , so it supports convergent validity of all constructs. The results of discriminant validity for all constructs are at high significant level.

Table 3 shows ranking variable based on their mean to determine the importance of variable of this study. According to the results, unpredictable government policies have the highest priority among the items and lack of university-level education has the lowest priority.

Table 2. Reliability of Constructs and Convergent Validity

\begin{tabular}{lcccc}
\hline \multicolumn{1}{c}{ Construct } & $\begin{array}{c}\text { Composite } \\
\text { Reliability }\end{array}$ & $\begin{array}{c}\text { Cronbach's } \\
\text { Alpha }\end{array}$ & AVE \\
\cline { 2 - 2 } $\begin{array}{l}\text { Lack of Mana- } \\
\text { gerial Training } \\
\text { and Experience }\end{array}$ & 0.829 & 0.828 & 0.745 \\
$\begin{array}{l}\text { Inadequate Edu- } \\
\text { cation and Skills }\end{array}$ & 0.891 & 0.756 & 0.803 \\
$\begin{array}{l}\text { National Policy } \\
\text { and Regulatory }\end{array}$ & 0.841 & 0.622 & 0.726 \\
$\begin{array}{l}\text { Environment } \\
\text { Technological }\end{array}$ & 0.901 & 0.781 & 0.820 \\
$\begin{array}{l}\text { Change } \\
\text { Lack of Market } \\
\text { information }\end{array}$ & 0.903 & 0.786 & 0.823 \\
Lack of Credit & $\underline{0.915}$ & $\underline{0.86}$ & $\underline{0.781}$ \\
\hline
\end{tabular}

Table 3. Mean Ranking of Items

\begin{tabular}{lc}
\hline \multicolumn{1}{c}{ Item } & Mean Rank \\
\hline Unpredictable government policies & 3.74 \\
Lack of access to long-term credit & 3.72 \\
Undeveloped capital market & 3.65 \\
Lack of sufficient market information & 3.59 \\
Lack of freedom to credit choice & 3.56 \\
Unfamiliarity with new technologies & 3.34 \\
Grand corruption & 3.34 \\
Management style & 3.26 \\
Either not locally available or not affordable or & 3.26 \\
not situated to local condition & \\
Poor connectivity & 3.20 \\
Poor managerial ability & 3.16 \\
Not quite well equipped in education and skills & 3.00
\end{tabular}

Table 3, cont.

\begin{tabular}{ll}
\hline Lack of educational background & 2.69 \\
Lack of university level education & $\underline{2.55}$ \\
\hline
\end{tabular}

Interview method through focus group discussion was the next step to enrich the interpretation of data. Six informants who are SME owners have been selected for in-depth interviews related to the result of factor analysis.

In Indonesia, one of the factors that prevented SMEs to grow is low managerial capability. Although the demand for their businesses increases often the demand cannot be met because their resources are unprepared. Capital also becomes one of the obstacles in developing SMEs. Most SMEs are lack of business experience so they run the business without any plan, control, and evaluation of business activities. Thus, many SMEs are difficult to develop and eventually go bankrupt. From a bank perspective, that was because SMEs have not been able to manage its finances. Managerial training is very important for SMEs to increase the ability to innovate in order to improve their competitive advantage.

SME business actors often face problems in developing their business due to low entrepreneurial skills and competencies. Education only is not enough to succeed but needs to be equipped with skills and experience. On the other hand, skill only without education cannot make a successful business. The majority of SMEs were equipped with product-making skills but lack of business knowledge. Most informants uttered that education is not only seen from the level of formal education but the most important is SME must obtain entrepreneurship education through training, coaching, and mentoring from the government or other agencies.

Government policy to cultivate SMEs is not yet fully conducive. Unhealthy competition between small and large business still frequently happens and it makes SMEs harder to survive. Besides, SMEs are now facing global competition especially after the implementation of the ASEAN Economic Community (AEC) which Indonesia is one of the ASEAN members. SMEs' products are now competing with cheaper products from other countries so innovation is the key to winning the competition.

Technology in Indonesia began to grow more rapidly since the year 2000, especially when the internet was easily accessed by society. The biggest obstacles so far are the number of business actors who are still reluctant to know internet technology. They still feel that buying much internet quota is less important to improve business strategy as innovation. They also feel unfamiliar with new technology especially digital marketing strategy which is very critical to compete in this era. In fact, by utilizing technology, information, and internet networks that are 
recently easier to access and use may help to develop the business. SME must be a fast learner of technology if they do not want to be left behind by competitors.

The free market demands the readiness of SMEs to compete. SMEs need to get information about the market factors easily and quickly to expand the marketing network of products and services. Market information requires: what kind of goods or products are needed by consumers in the certain area, how big the purchasing power of consumers, what is the appropriate market price, and what kind of consumer tastes on local, regional, and international markets. Complete and accurate market information can be utilized by SMEs to develop appropriate business plan and innovation. SMEs must be able to update information through various media especially digital media, so good internet connectivity is necessary.

SMEs especially micro business actors are generally difficult to get a loan from a bank because they do not have collateral such as land certificates. There are many requirements that must be fulfilled by SMEs and the process to get the loan with lowinterest rates is complicated. Banks do need collateral and not easy to provide capital loans to avoid bad credits. There is various Corporate Social Responsibility (CSR) funding from state and private companies that help SMEs in credits. The problem is CSR funding for SMEs often provide a capital loan but not for SME's business development itself.

\section{CONCLUSION}

Government participation is needed to accelerate the economic development and competitiveness of SMEs because of the SME limitations such as low quality of the products, limited knowledge and equipment, lack of technical knowledge and market information, and lack of capital. Seeing these conditions, the Surabaya government should continue to reinforce the policies for SMEs development to compete for not only in local but in the global market. Some suggestions to utilize innovative opportunities by overcoming the existing challenges are the followings:

Firstly, make a regional funding program that supports SMEs' growth through capital investment and job creation. The government should implement severe selection to choose the best SMEs and provide technical guidance related to SMEs' financial management by providing an understanding of how to write financial reports and manage finances. It is expected that SMEs can get funding from banks and improve SMEs' managerial ability.
Secondly, form a local community marketplace as one of the digital marketing strategies. In Surabaya, there are many entrepreneur communities of SMEs that can be collaborated in one marketplace to offer their products and services. This marketplace can be optimized in order to reach the global market. SMEs do not need to develop their own system because it will require additional investment but can participate in existing online business systems instead. The unity and teamwork of SMEs are necessary to compete with other countries' products.

Thirdly, provide technology or digital training programs. Surabaya government already delivered 'Gapura Digital' program, but it still needs intensive assistance so that SMEs can continue to be consistent in improving technological literacy.

Finally, provide business management training and mentoring program to improve the quality of SMEs' business and managerial skills. That can be accomplished by regularly working with academicians and practitioners and developing integrated training systems

\section{REFERENCES}

Alizadeh, M, Shabani, S, \& Fakhimi, R. 2011. An entrepreneurial model of commercialization in science and technology parks. International Conference of Science \& Technology Parks. Proceedings Isfahan, Nov. 2011. Taheran Iran. Asian Divisions Conference on Science and Technology Parks.

Farsi, J. Y., Toghraee \& Taghi, M. 2014. Identification the main challenges of small and medium sized enterprises in exploiting of innovative opportunities (Case study: Iran SMEs). Journal of Global Entrepreneurship Research 4: 4.

Howells, J., James, A., \& Malik, K. 2003. The sourcing of technological knowledge: distributed innovation processes and dynamic change. $R \& D$ Management 33(4): 395-409.

Hulland, J. 1999. Use of partial least squares (PLS) in strategic management research: a review of four recent studies. Strategic Management Journal 20(2): 195-204.

KO, H. T. \& Lu, H. P. 2010. Measuring innovation competencies for integrated services in the communications industry. Journal of Service Management 21(2): 162-190.

Magnus, H. Mats, M \& Maureen, M. 2007. What are innovative opportunities? Industry and Innovation 14(1): 27-45.

Maier, A., Keppler, T. \& Maier, D. 2014. Innovation the new trend in today's challenging economy. In The Bucharest University of Economic Studies. The 13th International Conference on Informatics in Economy, Education, Research \& Business Technologies. Proceedings. Bucharest, 15-18 May 2014.

Nybakk, E., \& Jenssen, J. I. 2012. Innovation strategy, working climate, and financial performance in traditional manufacturing firms: An empirical analysis. International Journal of Innovation Management 16(2): 26.

Sag, S., Sezen, B. \& Guzel, M. 2016. Factors That Motivate or Prevent Adoption of Open Innovation by SMEs in Developing Countries and Policy Suggestions. Procedia - Social and Behavioral Sciences 235: 756 - 763. 